\title{
Comparison of three restriction endonucleases in IS 1245-based RFLP typing of Mycobacterium avium
}

\author{
C. GARZELLI, NICOLETTA LARI, B. NGUON, MICHELA CAVALLINI, M. PISTELLO and \\ G. FALCONE
}

Department of Biomedicine, University of Pisa, I-56127 Pisa, Italy

\begin{abstract}
IS1245-based restriction fragment length polymorphism (RFLP) analysis has been proposed recently for molecular typing of Mycobacterium avium isolates. As there is no standardised method with respect to the optimal restriction enzyme, three restriction endonucleases were tested for analysis of 17 human isolates. The restriction endonucleases, selected on the basis of the physical maps of IS1245 and of the highly homologous IS1311, were BsaAI, that cleaves IS1245, PvuII, that cleaves IS1311, and NruI, that cleaves both IS1245 and IS1311. All the restriction endonucleases yielded polymorphic and complex RFLP patterns. However, BsaAI- and NruI-generated bands were more evenly distributed and easier to detect than PvuII-generated bands, most of which clustered in a narrow zone of the fingerprint. In some cases, DNA digestion with BsaAI or NruI yielded probe-specific restriction fragments of molecular size lower than expected. Moreover, digestion with $\mathrm{NruI}$, which was expected to generate the highest numbers of bands in all the isolates, yielded fewer bands than were obtained with BsaAI or PvuII in 14 and 5 isolates, respectively. These findings might suggest the existence of unidentified IS1245-related insertion element(s) in $M$. avium isolates. Computer analysis of the IS1245-based RFLP patterns of $M$. avium isolates showed that the restriction endonucleases were capable, although with minor differences, of defining distinct banding patterns and clusters of identical or highly related isolates, thus confirming IS1245-based RFLP analysis as a useful technique for epidemiological studies.
\end{abstract}

\section{Introduction}

Mycobacterium avium, long recognised as a primary pathogen of birds, behaves as an opportunist human pathogen that can be isolated from environmental, animal and human sources [1]. In immunocompetent patients, it causes pulmonary infections and cervical lymphadenitis [2] and, occasionally, soft tissue infections [3]. However, in a high proportion (25-50\%) of patients with the acquired immunodeficiency syndrome (AIDS), $M$. avium causes severe disseminated infections $[4,5]$.

The sources of human infection by $M$. avium and routes of transmission are not completely clear. Therefore, the availability of $M$. avium strain-specific markers might provide a basis for epidemiological studies which could define the environmental sources and the routes of transmission and, possibly, identify clones virulent for man. A number of methods for

Received 3 Dec. 1996; revised version accepted 16 April 1997.

Corresponding author: Dr C. Garzelli. typing $M$. avium isolates have been reported, including serotyping [6], multi-locus enzyme electrophoresis [7, 8], pulsed-field gel electrophoresis for analysis of large restriction fragments of genomic DNA [9], and the polymerase chain reaction (PCR) [10]. Recently, methods based on restriction fragment length polymorphism (RFLP) have been proposed $[11,12]$ resulting from the variability of the copy number and the chromosomal location of mycobacterial insertion sequences (IS).

Several IS have been reported in $M$. avium, although not all are useful for RFLP analysis. For example, IS 901 and IS902 share $98 \%$ homology at the DNA level $[13,14]$, and are of limited utility for differentiation of $M$. avium isolates because of a very low degree of mobility and limited polymorphism [12, $15,16]$. IS 1110 , a highly mobile insertion element of the IS 900 family, shows c. $60 \%$ homology with IS 901 and IS902, and is uncommon in $M$. avium isolates because of its recent acquisition [15]. As a consequence, it is not useful for epidemiological studies. On the other hand, the recently identified IS 1245 , a 1414bp element belonging to the IS256 family of IS, seems 
to represent a suitable candidate for IS-based RFLP of $M$. avium, in that it is limited to $M$. avium and is not found in $M$. intracellulare or in other mycobacterial species. Furthermore, it is present in a high copy number in $M$. avium strains isolated from human and animal sources [11]. Very recently, another insertion element, named IS 1311 , which shows $85 \%$ homology at the DNA level with IS1245, has been detected in $M$. avium [11, 12].

IS1245-based RFLP analysis of $M$. avium entails the growth of the organism, extraction of DNA, restriction endonuclease digestion, Southern blotting, and probing for the IS element. As there is no standardisation yet with respect to the optimal choice of restriction endonuclease for IS1245-based RFLP analysis, three restriction endonucleases were tested for an optimal discrimination of IS1245-based RFLP patterns in the typing of $M$. avium.

\section{Materials and methods}

\section{Bacterial strains}

M. avium strains were isolated from clinical specimens by the radiometric Bactec system (Becton Dickinson) according to standard procedures and identified by molecular probes (Gen-Probe, San Diego, CA, USA). A total of 17 isolates was included in the present study; 15 isolates were from HIV-positive patients (13 from blood, one from urine, one from sputum); two isolates were from sputum of HIV-negative individuals.

\section{Genomic DNA isolation}

$M$. avium strains were grown on liquid Middlebrook medium (Becton Dickinson); c. $1.5 \mathrm{ml}$ of the bacterial cultures were collected into a microcentrifuge tube and heated at $80^{\circ} \mathrm{C}$ for $20 \mathrm{~min}$ to kill the bacteria. The bacterial pellet was then collected by centrifugation for $5 \mathrm{~min}$ at $12000 \mathrm{~g}$ and suspended in $400 \mu \mathrm{l}$ of TE buffer $(0.01 \mathrm{M}$ Tris- $\mathrm{HCl}, \mathrm{pH} \quad 8.0 ; 0.001 \mathrm{M}$ EDTA). Lysozyme was added to a final concentration of $1.25 \mathrm{mg} / \mathrm{ml}$ and the tube was incubated at $37^{\circ} \mathrm{C}$. After overnight incubation, $70 \mu \mathrm{l}$ of SDS $10 \%$ and $5 \mu \mathrm{l}$ of proteinase $K(10 \mathrm{mg} / \mathrm{ml})$ were added and the tube was incubated for $12 \mathrm{~min}$ at $65^{\circ} \mathrm{C}$. To remove cell wall debris, denatured protein and polysaccharides, $100 \mu \mathrm{l}$ of $5 \mathrm{M} \mathrm{NaCl}$ and $100 \mu \mathrm{l}$ of $\mathrm{N}$-cetyl-N,N,N-trimethyl ammonium bromide (CTAB) $(100 \mathrm{mg} / \mathrm{ml}$ in $0.7 \mathrm{M}$ $\mathrm{NaCl}$ ) were added; after $10 \mathrm{~min}$ at $65^{\circ} \mathrm{C}, 750 \mu \mathrm{l}$ of chloroform isoamyl alcohol (24:1 v:v) were added and the mixture was vortex mixed for $15-20 \mathrm{~s}$. After centrifugation for $7 \mathrm{~min}$ at $12000 \mathrm{~g}$, DNA was precipitated by adding 1 volume of isopropanol to the aqueous supernate. After $30 \mathrm{~min}$ at $-20^{\circ} \mathrm{C}$ the mixture was centrifuged for $15 \mathrm{~min}^{2}$ at $12000 \mathrm{~g}$, the pellet was washed once with ethanol $70 \%$, air-dried and finally dissolved in TE buffer. DNA concentration was estimated by reading the optical density at 260 and
$280 \mathrm{~nm}$ in a Gene Quant II spectrophotometer (Pharmacia Biotech).

\section{Chromosomal DNA digestion and Southern blotting}

Chromosomal DNA $(4.5 \mu \mathrm{g})$ of each strain was digested overnight at $37^{\circ} \mathrm{C}$ with $6 \mathrm{U}$ of the restriction endonuclease BsaAI (BioLabs, USA), $10 \mathrm{U}$ of the restriction endonuclease $\mathrm{NruI}$ (Amersham), or $12 \mathrm{U}$ of the restriction endonuclease $P v u$ II (Boehringer Mannheim, Germany) in a final volume of $20 \mu \mathrm{l}$. The DNA fragments generated were separated electrophoretically on an agarose $0.8 \%$ gel and stained with ethidium bromide $0.5 \mu \mathrm{g} / \mathrm{ml}$. A mixture of $P v u I I$-digested supercoiled DNA ladder (Gibco BRL) and Hae IIIdigested ФX174 DNA (Boehringer Mannheim) was run in two lanes of each gel and served as molecular size markers ranging from 16.2 to $0.603 \mathrm{~kb}$. Electrophoresis was at $3.2 \mathrm{~V} / \mathrm{cm}(100 \mathrm{~V})$ for $10 \mathrm{~min}$ and at $0.8 \mathrm{~V} / \mathrm{cm}$ $(25 \mathrm{~V})$ overnight in a GNA 200 gel apparatus (LKBPharmacia, Sweden). DNA fragments were denatured with $0.25 \mathrm{M} \mathrm{HCl}$ for $10 \mathrm{~min}$ and, after two washes with $0.4 \mathrm{M} \mathrm{NaOH}$ for $20 \mathrm{~min}$, blotted on to a nylon filter (Hybond N-plus membrane; Amersham) by vacuum for $180 \mathrm{~min}$.

\section{IS1245 probe}

A 427-bp probing sequence for IS 1245 fragment was prepared from DNA of an $M$. avium isolate by PCR, as described previously [11], with oligonucleotides P1 5'GCCGCCGAAACGATCTAC and P2 5'AGGTGGCGTCGAGGAAGAC as primers. Briefly, PCR was performed in $0.5-\mathrm{ml}$ microcentrifuge reaction tubes in a final volume of $50 \mu \mathrm{l}$ containing $10 \mathrm{mM}$ Tris- $\mathrm{HCl}(\mathrm{pH}$ 8.8), $1.5 \mathrm{mM} \mathrm{MgCl}_{2}, 50 \mathrm{mM} \mathrm{KCl}$, Triton X-100 0.1\%, $25 \mu \mathrm{M}$ primers $\mathrm{P} 1$ and $\mathrm{P} 2,200 \mu \mathrm{M}$ deoxynucleoside triphosphates, $1.25 \mathrm{U}$ of Taq polymerase (Dynazyme) and $15 \mathrm{ng}$ of $M$. avium DNA. The mixture was overlaid with $75 \mu \mathrm{l}$ of mineral oil to prevent evaporation. The reaction was subjected to 30 cycles of amplification $\left(1 \mathrm{~min}\right.$ at $94^{\circ} \mathrm{C}, 1 \mathrm{~min}$ at $65^{\circ} \mathrm{C}, 1 \mathrm{~min}$ at $72^{\circ} \mathrm{C}$ ) and one final 10 -min incubation at $72^{\circ} \mathrm{C}$ in an OmniGene temperature cycler (Hybaid). The 427-bp amplificon was purified by Sephadex G-50 chromatography column, precipitated with ethanol $96 \%$ and solubilised with TE buffer.

\section{Labelling of probes}

IS1245 probe and molecular size standard probes, i.e., $P v u$ II-digested supercoiled ladder DNA and Hae IIIdigested $\Phi$ X174 DNA, were covalently labelled with horseradish peroxidase (HRP) by glutaraldehyde according to the procedure of the ECL Direct System (Amersham). 


\section{Hybridisation and detection}

After one wash in buffer $2 \times \mathrm{SSC}(0.3 \mathrm{M} \mathrm{NaCl}, 30 \mathrm{mM}$ sodium citrate, $\mathrm{pH} 7.0$ ), nylon filters were prehybridised by incubating in $10-12 \mathrm{ml}$ of hybridisation buffer (ECL Direct System, Amersham) for $15 \mathrm{~min}$ at $42^{\circ} \mathrm{C}$ in roller bottles in a hybridisation oven (Hybaid). The formulation of the buffer supplied in the ECL kit includes $6 \mathrm{M}$ urea which is equivalent to $50 \%$ formamide in reducing the $T_{m}$ of hybridisation. Filters were then hybridised by the addition of $c .200 \mathrm{ng}$ of IS 1245 probe and $25-40 \mathrm{ng}$ of each molecular size marker probe and incubation overnight at a temperature not exceeding $42^{\circ} \mathrm{C}$ in roller bottles at $6 \mathrm{rpm}$. Filters were then washed twice for $20 \mathrm{~min}$ at $42^{\circ} \mathrm{C}$ with a primary wash buffer ( $6 \mathrm{M}$ urea, SDS $0.4 \%, 0.5 \times \mathrm{SSC})$ in the roller bottles and then with a secondary wash buffer $(2 \times \mathrm{SSC})$ for no more than $15 \mathrm{~min}$ at room temperature on a shaking platform. Hybridisation was then detected on autoradiographic films by the enhanced chemiluminescence gene detection system (Hyperfilm-ECL; Amersham).

\section{Computer-assisted analysis of fingerprints}

The RFLP patterns were scanned with an Epson GT 8000 scanner at 200 dots/inch and $M$. avium fingerprints were compared by 3.1 GelCompar software (Applied Maths, Belgium; Windows version) in an IBM-compatible computer. The lanes were corrected for angle distortion and the RFLP patterns were normalised by equating external molecular size markers between the films. The Dice co-efficients of similarity [17] of all pairwise comparisons of patterns were calculated and a dendrogram of pattern relatedness constructed by UPGMA clustering, following the instructions of the GelCompar manufacturer. Similarity coefficients of fingerprints of a reference $M$. avium isolate run in different gels ranged between 85 and 95\%; accordingly, any two $M$. avium isolates with similarity coefficients $>85 \%$ were considered identical.

\section{Results and discussion}

For IS1245-based RFLP analysis of $M$. avium isolates, the selection of the restriction endonuclease and the DNA probe are critical. Ideally, the use of a restriction endonuclease which cleaves the IS only once and a DNA probe which does not overlap the endonuclease site would result in fragments defining both the copy number and the chromosomal positions of the IS, i.e., the basis of the DNA polymorphism among the isolates. Fig. 1 shows the physical maps of IS 1245 and the highly homologous IS 1311 [11, 12], as well as the cleavage sites of restriction enzymes which generate blunt end fragments. For the present study, restriction endonucleases $B s a \mathrm{AI}$ and $P v u \mathrm{II}$, that cleave IS 1245 and IS 1311 , respectively, once and $N r u$ I, that cleaves both IS 1245 and IS1311 once were selected.

A 427-bp DNA sequence was used as a probe, prepared by PCR with IS1245-specific primers, as described by Guerrero et al. [11]. The probe sequence is $80 \%$ homologous to the target sequence on IS 1311 . Although the hybridisation conditions in the present
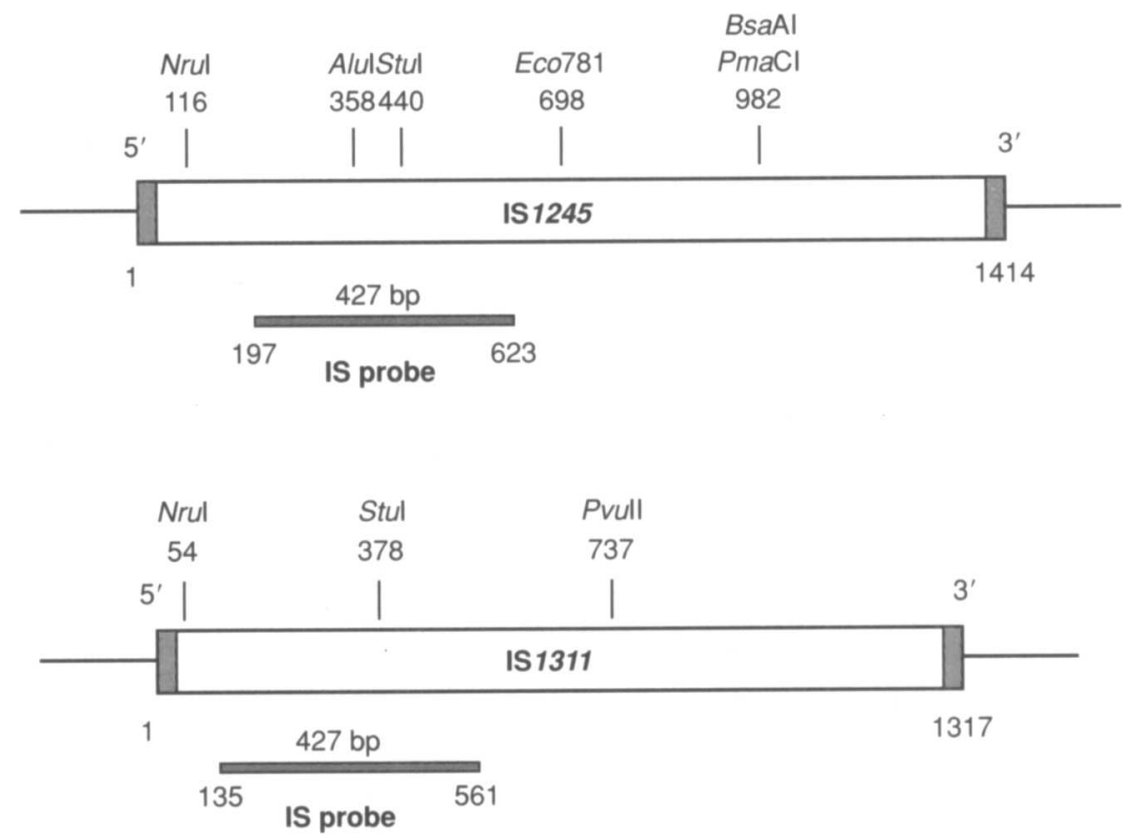

Fig. 1. Physical maps of the $M$. avium insertion elements IS 1245 and IS 1311 :(GeneBank accession numbers L33879 and U16276, respectively). The cleavage sites of restriction enzymes generating blunt end fragments (defined by computer program RESTRI, Pc/Gene, IntelliGenetics, CA, USA) are depicted. The light grey vertical bars represent the inverted repeats bordering IS DNA. The horizontal dark grey bar represents the 427-bp IS probe. The lines to the left and right denote chromosomal DNA. BsaAI cleaves IS 1245 at base pair 982 (CAC ${ }^{\circ}$ GTC); PvuII cleaves IS 1311 at base pair 737 (CAG ` CTG); NruI cleaves both IS 1245 and IS1311 at base pair 116 and 54 (TCG ` CGA), respectively. 
study include a relatively low $T_{m}$ temperature, i.e., $42^{\circ} \mathrm{C}$, which was necessary to prevent loss of peroxidase activity of the probe, and the formulation of the buffer ensured stringent conditions under which the DNA probe could also hybridise with the $80 \%$ homologous target sequence on IS1311.

The 427-bp probe does not overlap the cleavage sites of the selected enzymes (see Fig. 1). This indicates that only one of the two fragments into which each IS is cleaved by endonuclease digestion will hybridise with the probe. The minimal sizes of IS 1245 probe- hybridising restriction fragments generated by $B s a \mathrm{AI}$, NruI, or PvuII, as determined by the distance between the restriction site on the insertion element and a hypothetical chromosome restriction site located just outside the insertion element are approximately 0.98 , 1.26 and $0.74 \mathrm{~kb}$, respectively. Furthermore, the restriction enzyme $\mathrm{NruI}$, which cleaves both IS 1245 and IS1311, would be expected to generate in all isolates a number of IS 1245 probe-specific restriction fragments that is the sum of the copy number of the two insertion elements, each fragment containing one copy of either IS 1245 or IS 1311 fragments. On the

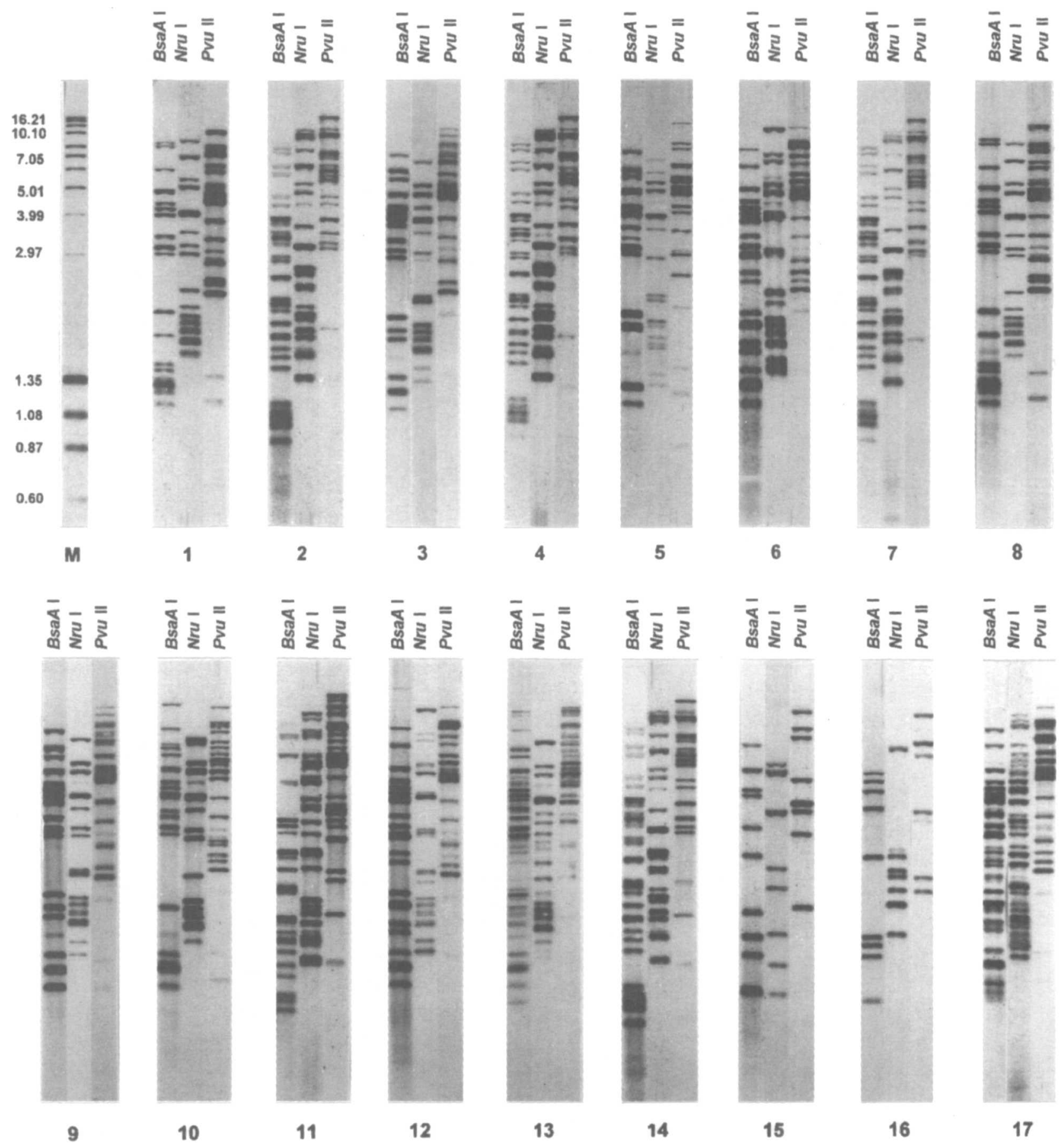

Fig. 2. DNA RFLP patterns of 17 M. avium isolates. Chromosomal DNA of each isolate, numbered at the bottom, was digested with restriction endonucleases BsaAI, NruI, or PvuII (indicated at the top of each panel). A 427-bp PCRamplified fragment of IS1245 was used as DNA probe. Lane M shows the marker fragments of DNA size (kb). 
other hand, BsaAI or PvuII endonucleases will generate probe-positive restriction fragments that may contain more than one IS; for example, digestion of genomic DNA with $B s a \mathrm{AI}$ may generate, depending on the location of $B s a \mathrm{AI}$ restriction sites on the chromosome, probe-positive restriction fragments containing: (i) one copy of IS 1245 , (ii) one copy of IS 1245 and one or more copies of IS1311, (iii) one or more copies of IS 1311 and no IS 1245 copy.

Fig. 2 shows the fingerprints of $17 \mathrm{M}$. avium isolates obtained by digestion of genomic DNA with the selected restriction endonucleases and by probing with the IS1245-derived 427-bp DNA sequence. The IS1245-based RFLP patterns were polymorphic and complex with all the restriction endonucleases tested. Under these electrophoresis conditions, $P v u \mathrm{II}$, which was the enzyme used for RFLP analysis of $M$. avium isolates in previously published reports [10-12], was the least satisfactory, as most of the PvuII-generated bands clustered in a narrow zone of the fingerprints and several faint bands appeared, especially in the low molecular size range. In contrast, Bsa AI- and NruIgenerated bands were more evenly distributed and easier to detect. In particular, similar to the results for strains studied by other authors $[10,11], \quad P v u$ II digestion of genomic DNA yielded 6-20 (average 14.6) probe-specific restriction fragments; $B s a \mathrm{AI}$ yielded 9-25 (average 18.6) restriction fragments of molecular size ranging approximately from 12.1 to $0.9 \mathrm{~kb}$; and NruI gave 7-27 (average 16.0) bands ranging approximately from 10.1 to $1.1 \mathrm{~kb}$.

Three $M$. avium isolates yielded one probe-specific
Table 1. Number of IS 1245 probe-specific bands generated by digestion with three restriction endonucleases

\begin{tabular}{lccc}
\hline & \multicolumn{3}{c}{ Number of bands* } \\
\cline { 2 - 4 } Isolate & Bsa AI & NruI & PvuII \\
\hline no. & 16 & 15 & 15 \\
2 & 23 & 17 & 14 \\
3 & 15 & 14 & 15 \\
4 & 24 & 19 & 12 \\
5 & 15 & 14 & 14 \\
6 & 24 & 18 & 16 \\
7 & 23 & 16 & 16 \\
8 & 17 & 15 & 15 \\
9 & 18 & 14 & 17 \\
10 & 17 & 13 & 19 \\
11 & 17 & 18 & 20 \\
12 & 21 & 13 & 15 \\
13 & 25 & 22 & 17 \\
14 & 21 & 22 & 14 \\
15 & 10 & 8 & 8 \\
16 & 9 & 7 & 6 \\
17 & 21 & 27 & 15 \\
\hline
\end{tabular}

*Bands were detected automatically by GelCompar software.

restriction. fragment of molecular size lower than expected on the basis of the physical maps of IS 1245 and IS1311; isolates 2 and 14 showed one band of $c$. $0.9 \mathrm{~kb}$ following DNA digestion with BsaAI and isolate 15 showed one band of $c .1 .1 \mathrm{~kb}$ following NruI digestion. These findings might be due to the presence of new restriction sites within some copies of the IS or to the deletion of part of the IS element. However, the existence in $M$. avium DNA of a novel IS1245-related element(s) can also be postulated. This hypothesis is further supported by the finding that the numbers of NruI-generated bands (see Table 1) were lower than those obtained with $B s a \mathrm{AI}$ and $P v u \mathrm{II}$ in

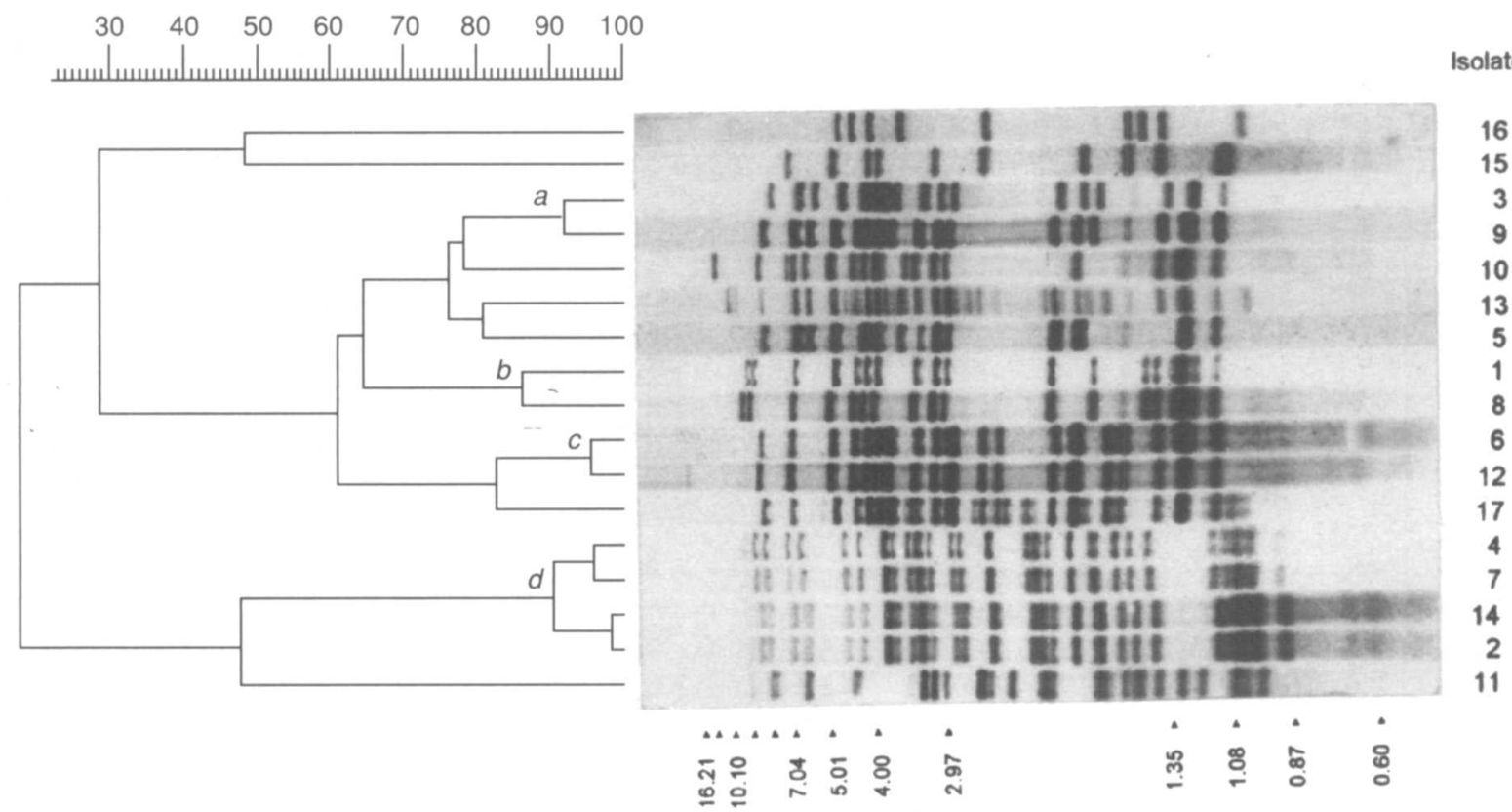

Fig. 3. Bsa AI-generated DNA RFLP patterns of $17 \mathrm{M}$. avium isolates. Banding patterns are ordered by similarity. Corresponding dendrograms are on the left. The position of bands in each lane has been normalised so that band positions of all strains are mutually comparable. The top scale depicts similarity coefficients. Numbers at the bottom indicate sizes $(\mathrm{kb})$ of standard DNA fragments; $a, b, c$, and $d$ indicate clusters of identical clones. 
14 and 5 of the $17 \mathrm{M}$. avium isolates, respectively, which is not consistent with the existence in these isolates of only IS1245 and IS1311. In fact, if the isolates contained only these two insertion elements, NruI, which can cleave both IS 1245 and IS 1311 once, should have generated in all the isolates the highest number of IS 1245 probe-specific restriction fragments, i.e., the sum of the copy number of the two insertion elements. The existence of unidentified insertion elements in $M$. avium has also been suggested by Roiz et al. [12].

To test whether the IS1245-based polymorphism generated by the different restriction endonucleases might represent a tool for the study of $M$. avium strain relatedness, the banding patterns obtained with each enzyme were studied for similarity by computer analysis and dendrograms were constructed to show the degree of relatedness among strains according to a previously described algorithm [18]. Results are shown in Figs. 3, 4 and 5 for $B s a \mathrm{AI}, N r u \mathrm{I}$, and PvuII, respectively. In $B s a \mathrm{AI}$-generated RFLP analysis (Fig. 3), 11 distinct banding patterns were found, as four banding patterns were shared by more than one isolate (i.e., by a cluster of isolates). Each cluster, indicated in Fig. 3 as $a, b, c$, and $d$, included fingerprints with $>85 \%$ similarity coefficient. One cluster $(d)$ contained four isolates (isolates $4,7,14,2$ ) and three

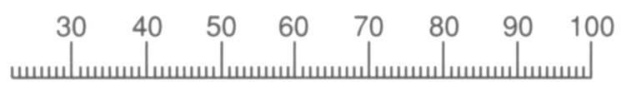

Isolate No.
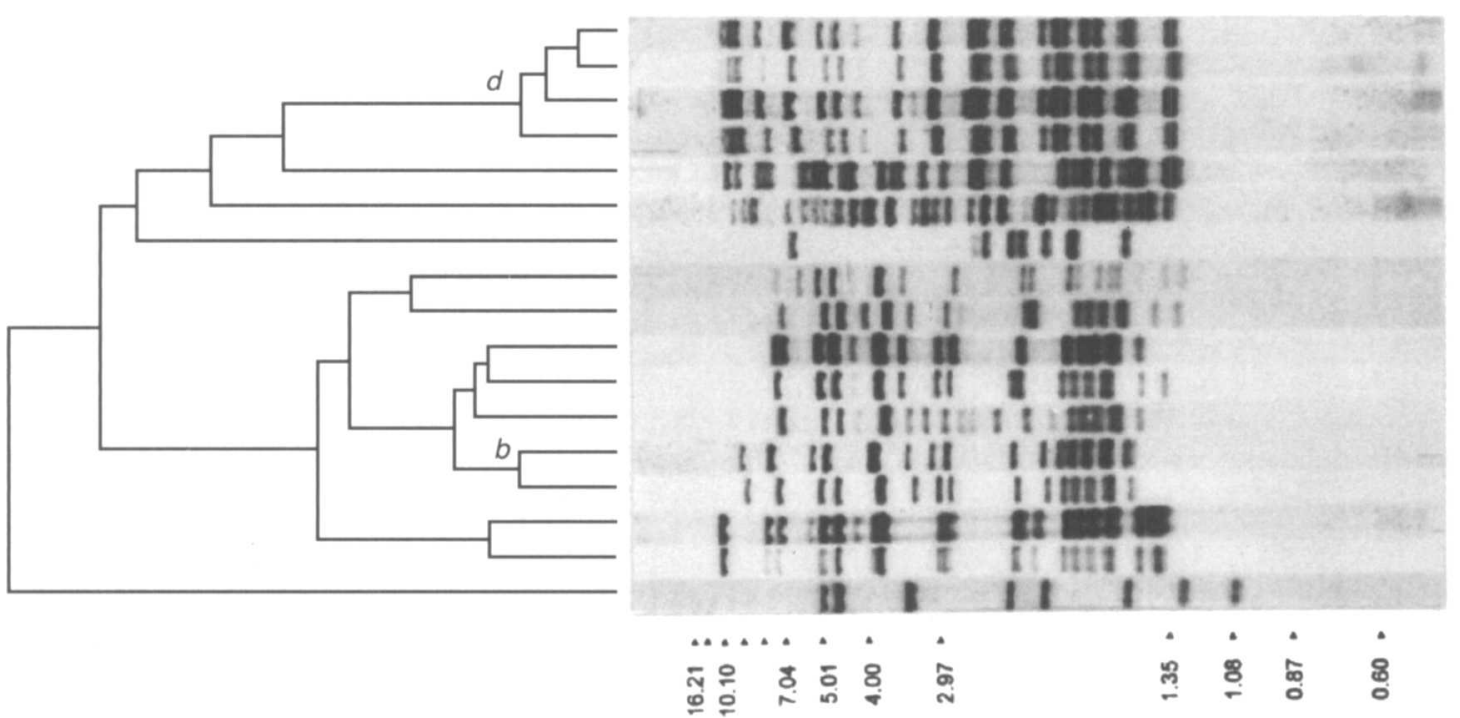

Fig. 4. NruI-generated DNA RFLP patterns of $17 \mathrm{M}$. avium isolates. See legend to Fig. 3 for further details.
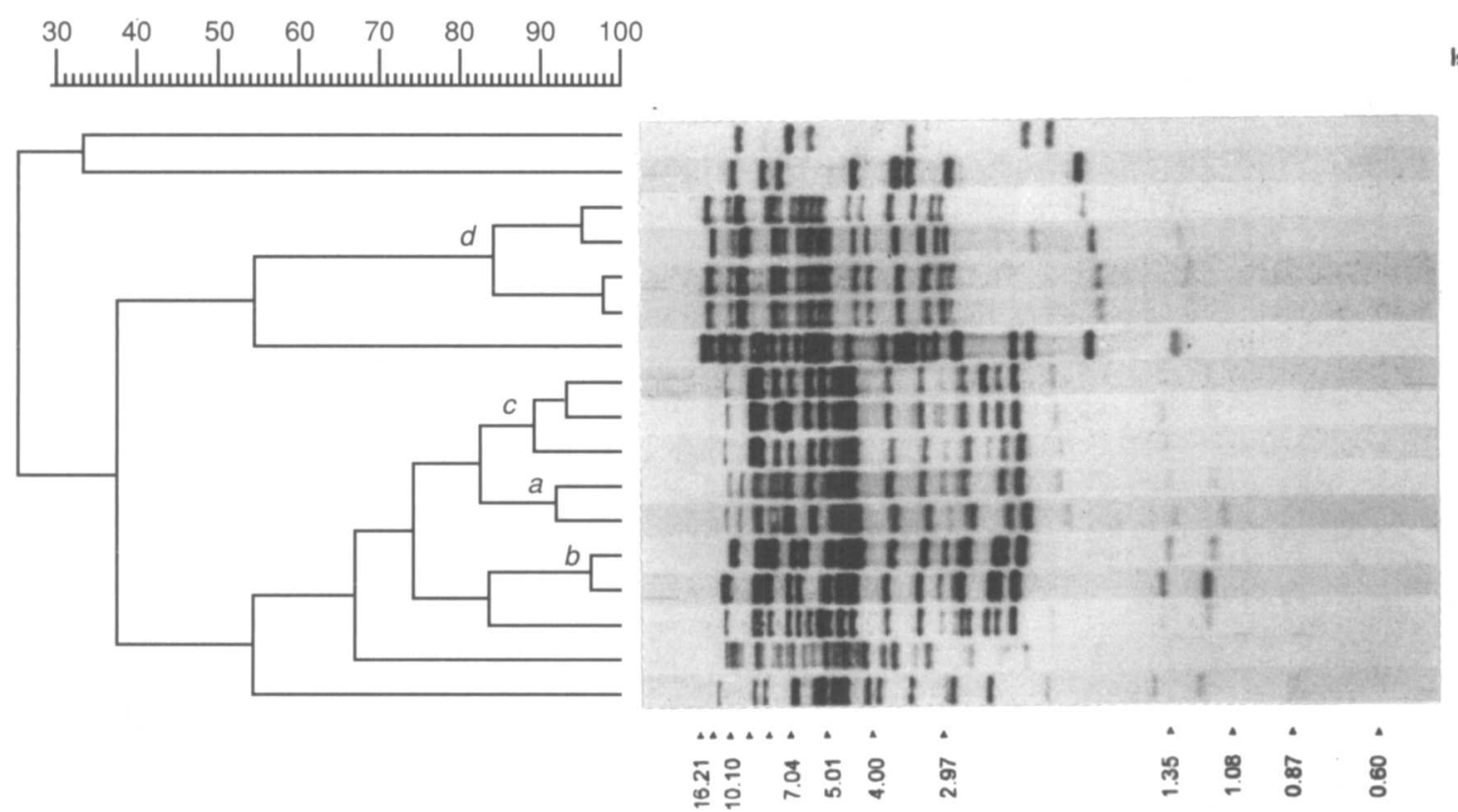

Isolate No.

Fig. 5. PvuII-generated DNA RFLP patterns of $17 M$. avium isolates. See legend to Fig. 3 for further details. 
clusters each contained two isolates (clusters $a, b$, and $c$ included isolates 3 and 9, 1 and 8, and 6 and 12, respectively). In NruI-generated RFLP analysis (Fig. 4), 13 distinct banding patterns were found. Again, isolates $4,7,14,2$, and isolates 1 and 8 occurred in two clusters (indicated as clusters $d$ and $b$, respectively). Isolates 3 and 9 and isolates 6 and 12 , (included in clusters $a$ and $c$, respectively, according to $B s a \mathrm{AI}$ analysis), showed a similarity coefficient $<85 \%$, as they differed by at least one band. In PvuII-generated RFLP analysis (Fig. 5), 11 distinct banding patterns were found. The clusters $a$ and $b$ again included isolates 3 and 9 and isolates 1 and 8 , respectively; cluster $c$ included three isolates (isolates 6,12 , and 17). Isolates $2,14,4$ and 7 , constituting a cluster of four isolates by $\mathrm{Bsa \textrm {AI }}$ and $\mathrm{NruI}$ analysis, were grouped in two highly related clusters with $84 \%$ similarity coefficient (clusters including isolates 2, 14 and 4,7 , respectively).

Thus, the different restriction endonucleases tested in the present study for the IS1245-based RFLP analysis of $M$. avium isolates are capable, although with minor differences, of defining distinct banding patterns and clusters of identical or highly related isolates. IS1245based RFLP analysis employing BsaAI and $N r u$ I restriction endonucleases is used in our laboratory for molecular typing of $M$. avium isolates and is capable of differentiating new from recurrent infections, as well as monoclonal from polyclonal infections, in HIV-positive patients (Garzelli et al. unpublished observations). IS1245-based RFLP analysis appears to be a suitable technique for the definition of genetic relatedness between $M$. avium isolates. However, it should be tested on numerous isolates in epidemiological studies for further validation. Standardisation of the technique, especially in respect of the choice of restriction endonuclease and probing sequence, is needed to permit comparison of results between different laboratories.

This work was supported by funds from Italian MURST (Fondi $40 \%$ - Controllo della patogenicità microbica).

\section{References}

1. Falkinham JO. Epidemiology of infection by nontuberculous mycobacteria. Clin Microbiol Rev 1996; 9: 177-215.
2. Inderlied CB, Kemper CA, Bermudez LEM. The Mycobacterium avium complex. Clin Microbiol Rev 1993; 6: 266-310.

3. Hellinger WC, Smilack JD, Greider JL et al. Localized softtissue infections with Mycobacterium avium/Mycobacterium intracellulare complex in immunocompetent patients; granulamatous tenosynovitis of the hand or wrist. Clin Infect Dis 1995; 21: 65-69.

4. Halik JA, Horsburgh CR, Metchock B, Williams PP, Fann SA, Thompson SE. Disseminated Mycobacterium avium complex infection: clinical identification and epidemiologic trends. $J$ Infect Dis 1992; 165: 577-580.

5. Horsburgh CR, Selik RM. The epidemiology of disseminated nontuberculous mycobacterial infection in the acquired immunodeficiency syndrome (AIDS). Am Rev Respir Dis 1989; 139: 4-7.

6. Schaefer WB. Serologic identification of the atypical mycobacteria and its value in epidemiologic studies. Am Rev Respir Dis 1967; 96: 115-118.

7. Wasem CF, McCarthy CM, Murray LW. Multilocus enzyme electrophoresis analysis of the Mycobacterium avium complex and other mycobacteria. J Clin Microbiol 1991; 29: 264-271.

8. Yakrus MA, Reeves MW, Hunter SB. Characterization of isolates of Mycobacterium avium serotypes 4 and 8 from patients with AIDS by multilocus enzyme electrophoresis. $J$ Clin Microbiol 1992; 30: 1474-1478.

9. Mazurek GH, Hartman S, Zhang $Y$ et al. Large DNA restriction fragment polymorphism in the Mycobacterium avium- $M$. intracellulare complex: a potential epidemiologic tool. J Clin Microbiol 1993; 31: 390-394.

10. Picardeau M, Vincent V. Typing of Mycobacterium avium isolates by PCR. J Clin Microbiol 1996; 34: 389-392.

11. Guerrero C, Bernasconi C, Burki D, Bodmer T, Telenti A. A novel insertion element from Mycobacterium avium, IS1245, is a specific target for analysis of strain relatedness. $J$ Clin Microbiol 1995; 33: 304-307.

12. Roiz MP, Palenque E, Guerrero C, Garcia MJ. Use of restriction fragment length polymorphism as a genetic marker for typing Mycobacterium avium strains. J Clin Microbiol 1995; 33: 1389-1391.

13. Kunze ZM, Wall S, Appelberg R, Silva MT, Portaels F, McFadden JJ. IS901, a new member of a widespread class of atypical insertion sequences, in association with pathogenicity in Mycobacterium avium. Mol Microbiol 1991; 5: 2265-2272.

14. Moss MT, Malik ZP, Tizard MLV, Green EP, Sanderson JD, Hermon-Taylor J. IS902, an insertion element of the chronicenteristis-causing Mycobacterium avium subsp. silvaticum. $J$ Gen Microbiol 1992; 138: 139-145.

15. Hernandez Perez $M$, Fomukong NG, Hellyer $T$, Brown $I N$, Dale JW. Characterization of IS 1110 , a highly mobile genetic element from Mycobacterium avium. Mol Microbiol 1994; 12, 717-724.

16. Kunze ZM, Portaels F, McFadden JJ. Biologically distinct subtypes of Mycobacterium avium differ in possession of insertion sequence IS901. J Clin Microbiol 1992; 30: 2366-2372.

17. Dice LR. Measures of the amount of ecologic association between species. Ecology 1945; 26: 297-302.

18. van Soolingen D, Hermans PWM, de Haas PEW, Soll DR, van Embden JDA. Occurrence and stability of insertion sequences in Mycobacterium tuberculosis complex strains; evaluation of an insertion sequence-dependent DNA polymorphism as a tool in the epidemiology of tuberculosis. J Clin Microbiol 1991; 29: $2578-2586$ 